\title{
Implantable Pump
}

National Cancer Institute

\section{Source}

National Cancer Institute. Implantable Pump. NCI Thesaurus. Code C16737.

A small device installed under the skin to provide long-term controlled-rate delivery of drugs such as chemotherapeutic agents or analgesics. Delivery rate may be externally controlled or osmotically or peristaltically controlled with the aid of transcutaneous monitoring. 